\title{
Article \\ Identification and Fine Mapping of a Locus Related to Leaf Up-Curling Trait (Bnuc3) in Brassica napus
}

\author{
Shubei Wan ${ }^{1} \oplus$, Zongping Qin ${ }^{1}$, Xiaomei Jiang ${ }^{1}$, Mao Yang ${ }^{1}$, Wenjing Chen ${ }^{1}$, Yangming Wang ${ }^{1}$, Fei $\mathrm{Ni}^{1}$, \\ Yijian Guan ${ }^{1}$ and Rongzhan Guan ${ }^{1,2, *}$ \\ 1 State Key Laboratory for Crop Genetics and Germplasm Enhancement, Nanjing Agricultural University, \\ Nanjing 210095, China; 2016201079@njau.edu.cn (S.W.); 2019101078@njau.edu.cn (Z.Q.); \\ 2019101077@njau.edu.cn (X.J.); 2017201033@njau.edu.cn (M.Y.); 2016201058@njau.edu.cn (W.C.);

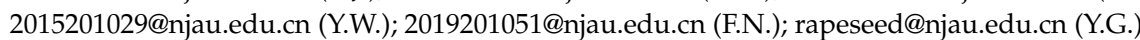 \\ 2 Jiangsu Collaborative Innovation Center for Modern Crop Production, Nanjing Agricultural University, \\ Nanjing 210095, China \\ * Correspondence: guanrzh@njau.edu.cn
}

check for updates

Citation: Wan, S.; Qin, Z.; Jiang, X.; Yang, M.; Chen, W.; Wang, Y.; Ni, F.; Guan, Y.; Guan, R. Identification and Fine Mapping of a Locus Related to Leaf Up-Curling Trait (Bnuc3) in Brassica napus. Int. J. Mol. Sci. 2021, 22, 11693. https://doi.org/ $10.3390 /$ ijms222111693

Academic Editor:

Tomotsugu Koyama

Received: 8 October 2021

Accepted: 24 October 2021

Published: 28 October 2021

Publisher's Note: MDPI stays neutral with regard to jurisdictional claims in published maps and institutional affiliations.

Copyright: (c) 2021 by the authors. Licensee MDPI, Basel, Switzerland. This article is an open access article distributed under the terms and conditions of the Creative Commons Attribution (CC BY) license (https:// creativecommons.org/licenses/by/ $4.0 /)$.

\begin{abstract}
Leaf trait is an important target trait in crop breeding programs. Moderate leaf curling may be a help for improving crop yield by minimizing the shadowing by leaves. Mining locus for leaf curling trait is of significance for plant genetics and breeding researches. The present study identified a novel rapeseed accession with up-curling leaf, analyzed the up-curling leaf trait inheritance, and fine mapped the locus for up-curling leaf property (Bnuc3) in Brassica napus. Genetic analysis revealed that the up-curling leaf trait is controlled by a single dominant locus, named BnUC3. We performed an association study of BnUC3 with single nucleotide polymorphism (SNP) markers using a backcross population derived from the homozygous up-curling leaf line NJAU-M1295 and the canola variety 'zhongshuang11' with typical flat leaves, and mapped the BnUC3 locus in a $1.92 \mathrm{Mb}$ interval of chromosome A02 of B. napus. To further map BnUC3, 232 simple sequence repeat (SSR) primers and four pairs of Insertion/Deletion (InDel) primers were developed for the mapping interval. Among them, five SSR markers and two InDel markers were polymorphic. By these markers, the mapping interval was narrowed to $92.0 \mathrm{~kb}$ using another $\mathrm{F}_{2}$ population. This fine mapping interval has 11 annotated genes among which BnaA02T0157000ZS were inferred to be candidate casual genes for up-curling leaf based on the cloned sequence analysis, gene functionality, and gene expression analysis. The current study laid a foundational basis for further elucidating the mechanism of BnUC3 and breeding of variety with up-curling leaf.
\end{abstract}

Keywords: up-curling leaf; mapping; Brassica napus L.

\section{Introduction}

In plants, the leaf, the primary photosynthetic organ, is vital for growth and development. Several leaf traits, including size and rolling, significantly influence plant production. Moderate leaf up-curling improves photosynthetic efficiency and increases yield. It reduces the incident solar radiations and leaf transpiration and subsequently provides drought resistance [1]. Therefore, mining the genes associated with leaf up-curling will uncover the underlying molecular mechanisms and help plant breeding.

In higher plants, few mechanisms leading to leaf curling have been discovered. The leaf-curling genes have been associated with leaf polarity establishment, cutin and cuticular wax biosynthesis, cell wall synthesis, and hormone responsiveness. In particular, leaf adaxial-abaxial polarity has been crucial for forming curled leaves [2,3]. PHANTASTICA (PHAN), encoding an MYB domain transcription factor, was first associated with adaxialabaxial polarity in Antirrhinum majus [4,5]. In Arabidopsis, ASYMMETRIC LEAVES 1 (AS1), a homolog of PHAN, regulates leaf adaxial polarity, forming a protein complex with the plant-specific lateral organ boundaries (LOB) family protein AS2 [6]. Another 
three members of the HD-ZIP III (Class III homeodomain-leucine zipper) gene family, including PHABULSA (PHB), PHAVOLUTA (PHV), and REVOLUTA (REV), have also been associated with leaf-rolling phenotype in Arabidopsis [7,8]. The loss-of-function mutants of HD-ZIP III genes in maize, rice, and cucumber had adaxial cells and rolled leaves [9-12]. Besides, KANADI (KAN) genes, the members of the GARP (Golden2, ARR-B, and Psr1) family of transcription factors, regulate leaf abaxial polarity establishment by inhibiting the expression of HD-ZIP III and AS2 in the abaxial of leaves [13-16]. KAN regulates the expression of downstream genes, such as $Y A B B Y$, which encodes YABBY domain proteins regulating leaf abaxial patterning [17-19]. AUXIN RESPONSE FACTORs (ARFs), including ETTIN (ETT, also known as ARF3), ARF4, and ARF2, form a complex with KAN implicated in abaxial polarity establishment [20-22]. Furthermore, few non-coding RNAs have also been found to be involved in establishing adaxial-abaxial polarity. The microRNAs miR165 and miR166 are known to target HD-ZIP III [16,23], while miR390 triggers the production of phasiRNAs from TAS3 ta-siRNA (trans-acting short interfering RNAs) transcripts, repressing the activity of ARFs [24-27]. Thus, various genes and noncoding RNAs affect cell wall biogenesis as leaf polarity signals, leading to mechanical heterogeneity of the cell wall [28].

Studies have also associated the genes shaping leaves with the process of leaf cell wall formation and maturation. In rice, RL14 (rolling-leaf14) encoding a 2OG-Fe (II) oxygenase family protein affects leaf water transport by altering secondary cell wall composition. Lossof-function mutation in RL14 resulted in leaf incurving by the shrinkage of bulliform cells on the adaxial side [29]. Moreover, cuticle wax is considered a critical factor affecting leaf shape. Eight Arabidopsis T-DNA insertion mutants, defective in cuticular wax biosynthesis, showed leaf-curling phenotype due to loosely arranged epidermal cells [30]. In maize, a mutation in the gene Zmsrl5 (semi-rolled leaf 5) related to cuticular wax biosynthesis changed leaf epidermal bulliform cells, resulting in semi-rolled phenotype [31]. Meanwhile, the transgenic Arabidopsis overexpressing SHINE, encoding an APETAL2 domain transcription factor that regulates wax biosynthesis, had up-curling leaves due to increased cuticular wax and curved-down edges [32].

Furthermore, phytohormones such as auxin and brassinosteroids are related to the formation of curled leaves [33]. The loss-of-function mutation in AUXIN RESISTANT6 (AXR6), encoding CULLIN1, a subunit of SCF (Skp1-Cullin-1-F-box) complex, showed reduced auxin response gene expression and rolled-leaf phenotype [34]. In Arabidopsis, the ULTRACURVATA1 (UCU1) gene, encoding an AtSK (formerly designated ASK) protein, is involved in the cross-talk between the auxin and brassinosteroid signaling pathway; leaves of the mutant $u c u 1$ were rolled spirally downward [35]. Meanwhile, the rolledleaf phenotype of Arabidopsis BRASSINOSTEROID-INSENSITIVE 1 (BRI1) mutant (bri1) indicated the role of $B R I 1$ in leaf shaping [36,37].

Germplasm with up-curling leaves have been used in rice and maize genetic improvement for elevating cereal crops yield [31]. To find the method to improve canola variety yield, our previous studies have mapped two loci associated with up leaf curling (BnUC1 and BnUC2) onto chromosome A05 of rapeseed (Brassica napus L.) [2,38], and our present study reports a new B. napus line NJAU-M1295 with up-curling leaves (Bnuc3). With this novel accession, we fine mapped the locus responsible for the up-curling trait by single nucleotide polymorphism (SNP) and other molecular markers, and identified the candidate gene for the trait based on gene sequencing and expression analyses. Further, we evaluated the effects of the locus on the photosynthetic properties. Our findings may help elucidate the mechanisms underlying the leaf trait and offer clues for breeding.

\section{Results}

\subsection{The Leaf Up-Curling Mutant Performance}

The NJAU-M1295 plant with up-curling leaves was crossed with the elite variety Zhongshuang 11 (ZS11) with typical flat leaves. Leaves of the $\mathrm{F}_{1}$ plants were curled up, similar to NJAU-M1295 (Figure 1), indicating up-curling as a dominant trait. 


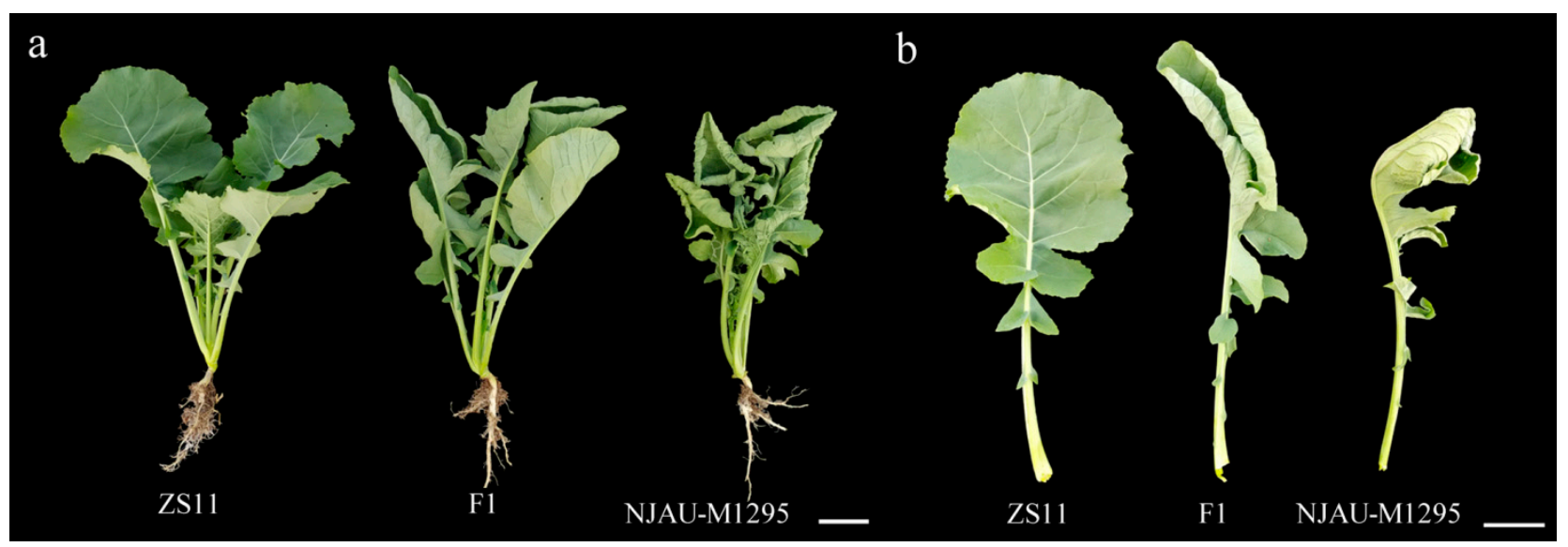

Figure 1. (a,b) Leaf phenotype at the seedling stage of ZS11, NJAU-M1295, and their $\mathrm{F}_{1}$ hybrid $(\mathrm{Bar}=5 \mathrm{~cm})$.

The leaf chlorophyll (Chl) content and photosynthetic indicators of the $\mathrm{F}_{2}$ population were determined to evaluate the effect of the up-curling of leaves. The leaf chlorophyll

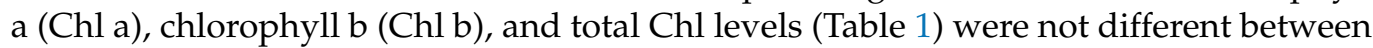
the plants with up-curling leaves and those with normal, flat leaves. Measurement of the gas-exchange parameters leaves. Meanwhile, the stomatal conductance, intercellular $\mathrm{CO}_{2}$ concentration, and leaf transpiration rate of up-curling leaves were significantly higher than those of flat leaves (Table 2). These observations indicate the negative effect of leaf up-curling on photosynthetic efficiency to a certain extent.

Table 1. Leaf chlorophyll contents of homozygous up-curling leaf and flat leaf in $\mathrm{F}_{2}$ population derived from NJAU-M1295 and ZS11 (mean $\pm \mathrm{SD}, \mathrm{n}=5$ for each sample).

\begin{tabular}{|c|c|c|c|c|}
\hline Genotye & Chl a (mg.g ${ }^{-1}$ FW) & Chl b (mg.g ${ }^{-1}$ FW) & Total Chl (mg.g ${ }^{-1}$ FW) & Chl a/Chl b \\
\hline flat leaf & $1.27 \pm 0.02$ & $0.60 \pm 0.03$ & $1.86 \pm 0.04$ & $2.12 \pm 0.08$ \\
\hline up-curling leaf & $1.26 \pm 0.05$ & $0.63 \pm 0.03$ & $1.90 \pm 0.08$ & $2.00 \pm 0.04$ \\
\hline
\end{tabular}

Table 2. Leaf photosynthetic indicators of homozygous up-curling leaf and flat leaf in the $\mathrm{F}_{2}$ population (mean $\pm \mathrm{SD}, \mathrm{n}=4$ for each sample).

\begin{tabular}{|c|c|c|c|c|}
\hline Genotye & $\begin{array}{l}\text { Net Photosynthetic Rate } \\
\left(\mu \mathrm{mol} \mathrm{CO} \mathrm{CO}_{2} \mathrm{~m}^{-2} \mathrm{~s}^{-1}\right)\end{array}$ & $\begin{array}{l}\text { Stomatal Conductance } \\
\left(\mathrm{mol} \mathrm{H}_{2} \mathrm{O} \mathrm{m}^{-2} \mathrm{~s}^{-1}\right)\end{array}$ & $\begin{array}{c}\text { Intercellular } \mathrm{CO}_{2} \\
\text { Concentration } \\
\left(\mu \mathrm{mol} \mathrm{CO} \mathrm{mol}^{-1}\right)\end{array}$ & $\begin{array}{c}\text { Transpiration Rate } \\
\left(\mathrm{mmol} \mathrm{H}_{2} \mathrm{O} \mathrm{m}^{-2} \mathrm{~s}^{-1}\right)\end{array}$ \\
\hline flat leaf & $20.86 \pm 1.62$ & $0.27 \pm 0.04$ & $236.25 \pm 8.31$ & $2.45 \pm 0.16$ \\
\hline up-curling leaf & $12.25 \pm 1.26^{* *}$ & $0.63 \pm 0.17^{* *}$ & $341.85 \pm 2.67^{* *}$ & $3.66 \pm 0.36^{* *}$ \\
\hline
\end{tabular}

Notes: ${ }^{* *}$ Indicates significant differences between up-curling leaf and flat leaf plants at 0.01 level by $t$-test.

\subsection{Inheritance of the Up-Curling Leaf Trait}

The NJAU-M1295 with up-curling leaves was crossed with two parents (ZS11 and NJAU-CP3756) with normal, flat leaves to produce $\mathrm{F}_{1}, \mathrm{~F}_{2}$, and backcross $\left(\mathrm{BC}_{1}\right)$ populations to clarify the genetic regulation of leaf shape. The leaf morphological traits of these populations were analyzed at seedling stage (Table 3). Data collected showed that the two $\mathrm{F}_{2}$ populations agreed with the expected Mendelian segregation ratio of $3: 1$, and two $\mathrm{BC}_{1}$ populations agreed with the expected Mendelian segregation ratio of $1: 1$. These results imply that the up-curling of leaves is a trait controlled by a single pair of dominant loci, referred to as BnUC3 in this study. 
Table 3. Inheritance of BnUC3 in populations derived from NJAU-M1295 vs. ZS11 and NJAU-CP3756 in B. napus.

\begin{tabular}{|c|c|c|c|c|c|c|}
\hline & Population & Leaf Up-Curling & Normal Leaves & Expected Ratio & $x^{2}$ & $p$ Value \\
\hline \multirow{4}{*}{$\begin{array}{c}\text { Cross I } \\
\text { NJAU-M1295 vs ZS11 }\end{array}$} & $\mathrm{F}_{1}$ & 87 & 0 & & & \\
\hline & $\mathrm{RF}_{1}$ & 77 & 0 & & & \\
\hline & $\mathrm{F}_{2}$ & 448 & 159 & $3: 1$ & 0.46 & 0.49 \\
\hline & $\mathrm{BC}_{1}$ & 86 & 92 & 1:1 & 0.20 & 0.65 \\
\hline \multirow{4}{*}{$\begin{array}{c}\text { cross II } \\
\text { NJAU-M1295 vs } \\
\text { NJAU-CP3756 }\end{array}$} & $\mathrm{F}_{1}$ & 91 & 0 & & & \\
\hline & $\mathrm{RF}_{1}$ & 79 & 0 & & & \\
\hline & $\mathrm{F}_{2}$ & 498 & 158 & $3: 1$ & 0.29 & 0.58 \\
\hline & $\mathrm{BC}_{1}$ & 106 & 113 & $1: 1$ & 0.22 & 0.64 \\
\hline
\end{tabular}

\subsection{Mapping of the BnUC3 Locus}

Thirty-seven individuals from the backcross population $(Z S 11 \times(Z S 11 \times N J A U-M 1295))$ were genotyped using a Brassica 60 K SNP BeadChip Array (Illumina, San Diego, CA, USA) which has 52,157 SNP markers. Then, the association of BnUC3 with SNPs was analyzed by genome-wide SNP scan using TASSEL 5 software [39]. In this analysis, the up-curling phenotype was given a value of 1 , and the normal phenotype was given a value of 0 . Results showed that the BnUC3 locus was tightly associated with two SNP markers, M49061 and M02825, on the A02 chromosome (Figure 2). Chi-square test $\left(\chi^{2}\right)$ was conducted to evaluate the association further (Table 4), indicating tight linkage between BnUC3 and the two markers. Additionally, the SNP genotypes between and near M49061 and M02825 were checked, and one recombinant was found between M49061 and BnUC3 and two between M02825 and BnUC3 in the backcross population with ZS11 as the recurrent parent. These observations indicated that BnUC3 was probably located in the $1922 \mathrm{~kb}$ long interval between M49061 and M02825 (Figure 3a).

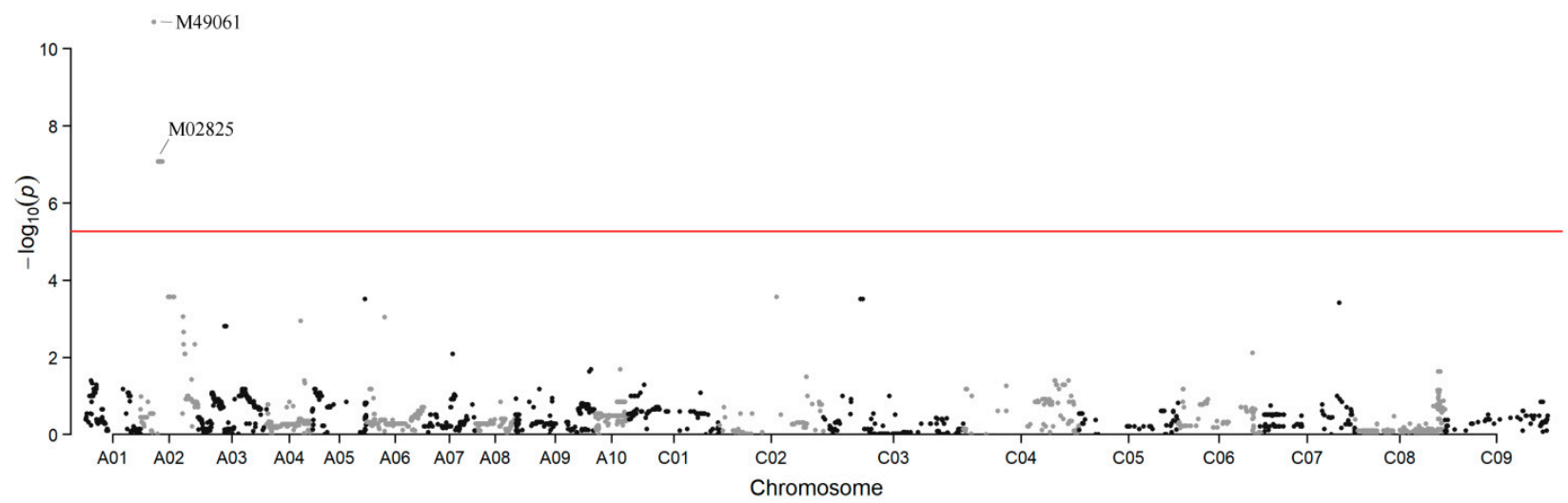

Figure 2. Manhattan plots of association analysis. Each dot represents an SNP. The horizontal red line represents the Bonferroni-corrected significance threshold $-\log 10(p)=5.27$.

Table 4. Contingency table of the two SNP markers vs leaf up-curling trait in $\mathrm{BC}_{1}$ of $\mathrm{ZS} 11 \times \mathrm{NJAU}$ M1295.

\begin{tabular}{cccccc}
\hline & M49061 & & \multicolumn{3}{c}{ M02825 } \\
\hline Ua -curling & Aa & & aa & Aa & aa \\
Normal flat leaf & 33 & & 1 & 32 & 2 \\
\hline$\chi^{2}$ & 0 & & 3 & 0 & 3 \\
\hline
\end{tabular}




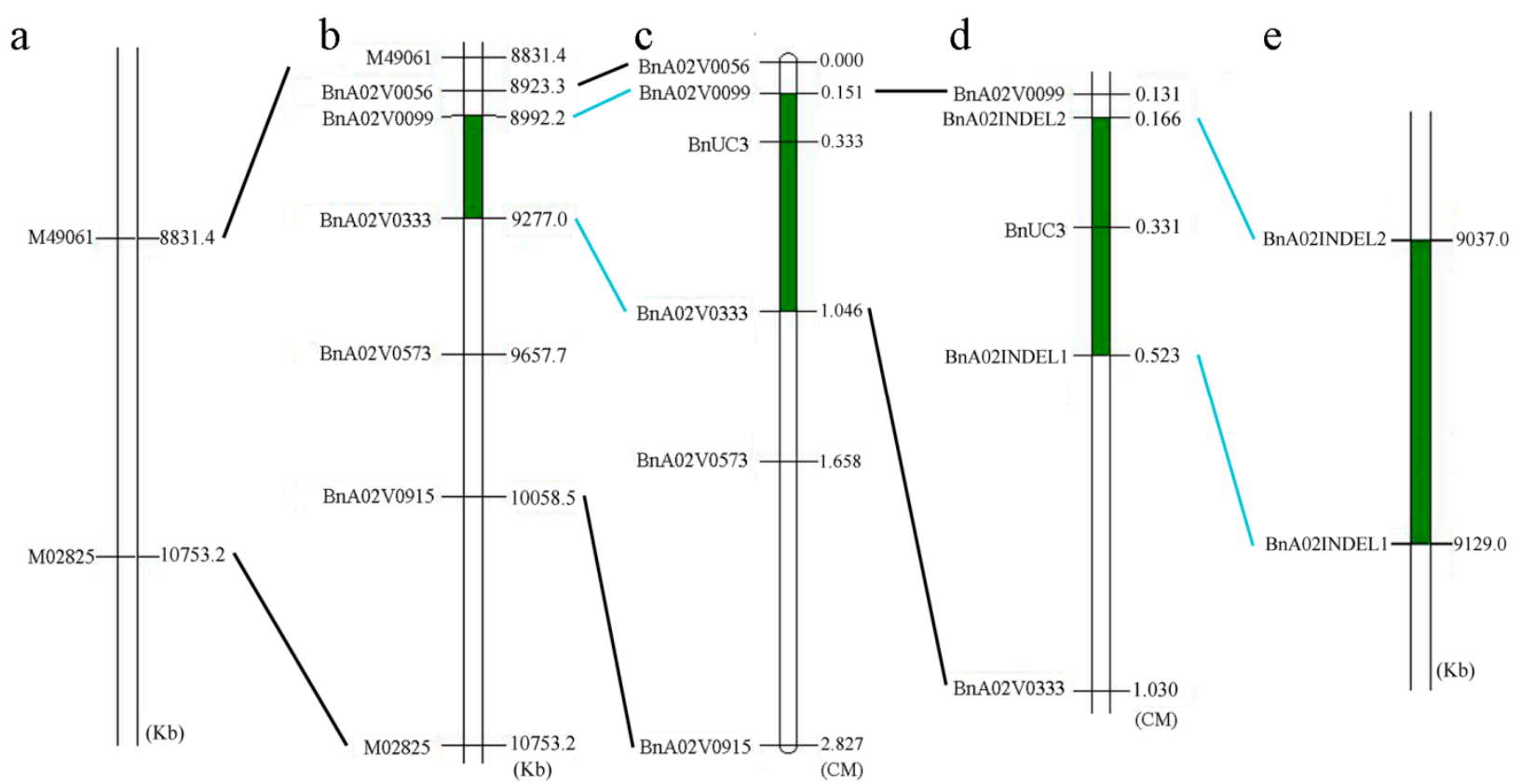

Figure 3. Mapping of the BnUC3 locus (a-e). M49061 and M02825 are SNP markers on chromosome A02. Markers with prefix BnA02V are SSR markers. BnaA02INDEL1 and BnaA02INDEL2 are InDel markers. Physical map location is based on ZS11 reference genome sequence.

However, no polymorphic SNP markers were detected between M49061 and M02825 in the backcross population. Besides, simple sequence repeat (SSR) markers developed also exhibited no polymorphism. Therefore, another mapping population was used to map BnUC3. The $\mathrm{F}_{2}$ population, derived from NJAU-M1295 with up-curling leaves and NJAU-CP3756 with flat leaves, was used. Then, 232 pairs of SSR primers were developed to screen the markers linked to the BnUC3 locus (see Table S1) using the replaced population with 584 individuals, based on the genomic sequence of the preliminary mapping interval. Analysis of the $\mathrm{F}_{2}$ population revealed five polymorphic SSR markers (BnaA02V0056, BnaA02V0099, BnaA02V0333, BnaA02V0573, and BnaA02V0915). These markers covered a distance of $2.827 \mathrm{cM}$, corresponding to $1135.5 \mathrm{~kb}$ (Figure $3 \mathrm{~b}, \mathrm{c}$ ).

Subsequently, the linkage map generated with JoinMap showed that BnUC3 was localized in the interval between BnaA02V0099 and BnaA02V0333, $0.182 \mathrm{cM}$ from BnUC3 to BnaA02V0099 (Figure 3b,c). No additional polymorphic SSR markers were found between BnaA02V0099 and BnaA02V0033. The renewed mapping interval genomic sequence of $B$. napus cv. ZS11 was compared with that of B. napus cv. Darmor (http:/ / www.genoscope. cns.fr/brassicanapus/, accessed on 25 October 2021) to narrow down the mapping interval, revealing some insertion/deletion (InDel) sites. Based on their sequence variation, four pairs of primers were developed, and two polymorphic InDel markers, BnaA02INDEL1 and BnaA02INDEL2, were obtained (Figure 4). Marks scanned in the $F_{2}$ population using these markers resulted in a narrowed mapping interval of $92.0 \mathrm{~Kb}(0.357 \mathrm{cM}$ long), with $B$. napus cv. ZS11 genome as the reference (Figure 3d,e). 


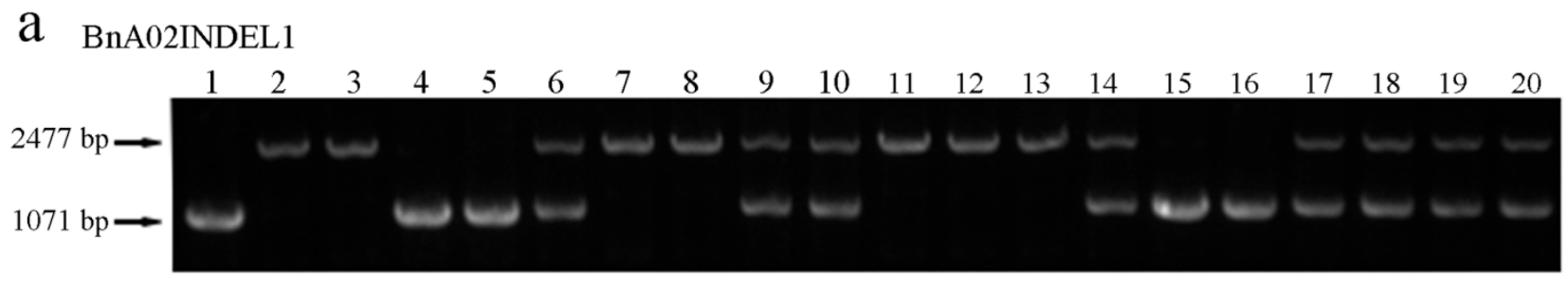

b BnA02INDEL2

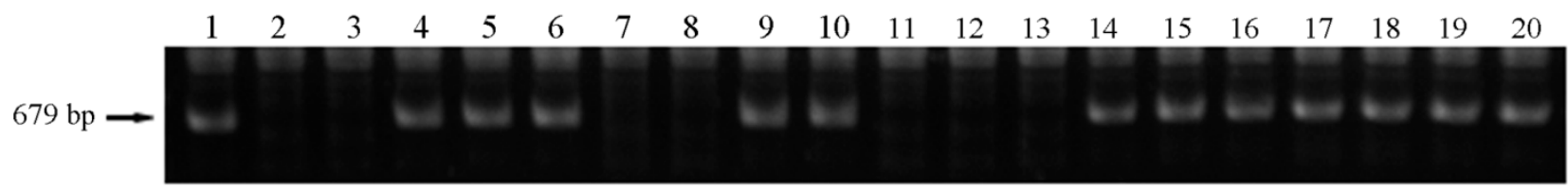

Figure 4. Partial molecular marker experimental results of the InDel mark BnaA02INDEL1 and BnaA02INDEL2. (a). The number $6,9,10,14,17,18,19$, and 20 denote the PCR products from heterozygous plants with up-curling leaves, and 1, 4, 5 , 15, and 16 denotes the PCR products from homozygous plants with up-curling leaves, and 2, 3, 7, 8, 11, 12, and 13 denote the PCR products from homozygous plants with flat leaves. (b). The number 1, 4, 5, 6, 9, 10, 14, 15, 16, 17, 18, 19, and 20 denote the PCR products from plants with up-curling leaves, and 2, 3, 7, 8, 11, 12, and 13 denote the PCR products from homozygous plants with flat leaves.

\subsection{Candidate Gene A nalysis}

The homologous segment sequences of the fine-mapped interval were downloaded from B. napus cv. ZS11 and Darmor, and the genes were annotated using $A$. thaliana annotation and ZS11 genome as the reference to identify the candidate genes associated with the leaf up-curling trait. The interval harbored 11 annotated genes (Table 5), and the genes BnaA02T0156700ZS, BnaA02T0157000ZS, and BnaA02T0157100ZS were listed as candidates. BnaA02T0156700ZS, homologous to AT1G65440, encodes a putative WG/GWrepeat protein (SPT6L) that regulates HD-ZIP III. Studies have associated this gene with the curly leaf formation in several species [12,40,41]. BnaA02T0157000ZS, homologous to AT1G65510, encodes a Brassicaceae-specific secreted transmembrane peptide (STMP). STMP overexpression led to small and curled leaves [42]. BnaA02T0157100ZS, homologous to AT1G65520, encodes an enoyl-CoA delta isomerase 1 (ECI1) that converts indole-3butyric acid (IBA) to active indole-3-acetic acid (IAA) [43]. This gene affects the IAA biosynthesis pathway and may be associated with the leaf up-curling [44]. Meanwhile, other genes in the mapping interval cannot be completely excluded from the candidate genes list, although they have not been associated with up leaf curling.

Table 5. Function annotation of genes in the mapping interval.

\begin{tabular}{cccc}
\hline $\begin{array}{c}\text { Gene in B.napus cv. } \\
\text { 'ZS11' }\end{array}$ & $\begin{array}{c}\text { Gene in B.napus cv. } \\
\text { 'Darmor' }\end{array}$ & $\begin{array}{c}\text { Homolog in } \\
\text { Arabidopsis thaliana }\end{array}$ & Putative Molecular Function \\
\hline BnaA02T0156200ZS & BnaA02g12060 & AT1G65295 & Ubiquitin carboxyl-terminal hydrolase \\
BnaA02T0156300ZS & BnaA02g12070 & AT1G65380 & CLAVATA2 I Leucine-rich repeat receptor-like protein \\
BnaA02T0156400ZS & BnaA02g12080 & AT1G65410 & NAP11 (NON-INTRINSIC ABC PROTEIN 11); \\
BnaA02T0156500ZS & BnaA02g12090 & AT1G65420 & Ycf20-like protein \\
BnaA02T0156600ZS & BnaA02g12100 & AT1G65430 & ARI8 I Probable E3 ubiquitin-protein ligase ARI8 \\
BnaA02T0156700ZS & BnaA02g12110 & AT1G65440 & GTB1 I Transcription elongation factor SPT6 homolog \\
BnaA02T0156800ZS & BnaA02g12120 & AT1G65450 & GLC I HXXXD-type acyl-transferase family protein \\
BnaA02T0156900ZS & BnaA02g12130 & AT1G65480 & FT I PEBP family protein \\
BnaA02T0157000ZS & & AT1G65510 & STMP I secreted transmembrane peptides \\
BnaA02T0157100ZS & BnaA02g12140 & AT1G65520 & ECI1 I Enoyl-CoA delta isomerase 1 \\
BnaA02T0157200ZS & BnaA02g12150 & AT1G65560 & Zinc-binding dehydrogenase family protein \\
\hline
\end{tabular}

Furthermore, the 11 genes' coding sequences (CDS) were cloned and sequenced with gene-specific primer pairs from the two parents of the mapping population (NJAU-M1295 
and NJAU-CP3756). Sequence alignments with ZS11 genome as the reference showed that gene coding sequence of BnaA02T0157000ZS has a nucleotide mutation in NJAU-M1295, causing a change in the functional product STMP at position 68 (Arg) into His in the plant with up-curling leaves (Figure 5). This mutation is in the disorder region as predicted by mobiDB-lite (https: / / www.ebi.ac.uk/interpro/, accessed on 25 October 2021), and it may have affected the peptide secretion function, and probably altered the leaf morphology. The other 10 genes in the mapping interval did not show sequence differences between NJAU-M1295 and NJAU-CP3756.

$\begin{array}{ll}\text { NJAU-M1295 } & \text { MGPKTSHKVALLVSLLLLILTLSSQARVIEAASRKLASGRNIVYTPSSKSCGATHATWKKKKRGPCRHPRTAPASYQSP } \\ \text { ZS11/NJAU-CP3756 MGPKTSHKVALLVSLLLLILTLSSQARVIEAASRKLASGRNIVYTPSSKSCGATHATWKKKKRGPCR RPPTAPASYQSP }\end{array}$

Signal peptide Disorder region

Figure 5. Amino acid sequence alignment of BnaA02T0157000ZS in NJAU-M1295, NJAU-CP3756, and ZS11.

The expression of the BnaA02T0157000ZS was analyzed by qRT-PCR using leaf samples from the $F_{2}$ subpopulation with up-curling leaves and the subpopulation with flat leaves. Analysis revealed significantly higher expression levels of BnaA02T0157000ZS in the plants with up-curling leaves than plants with flat leaves (Figure 6). In summary, as revealed by the gene sequencing and potential gene functionality analysis, the STMP mutation may be inferred to be responsible for the dominant leaf-curling trait.

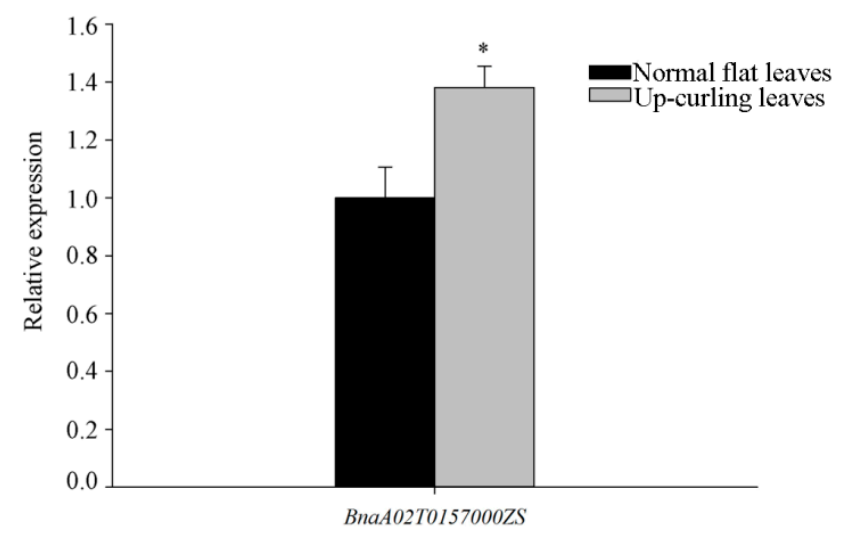

Figure 6. Gene expression analysis of BnaA02T0157000ZS by qRT-PCR in subpopulation with uprolling leaves (gray) and the subpopulation with flat leaves (black). Error bars represent the SE of three independent replicates. Statistical significance was calculated by two-tailed Student's $t$-test: * $p<0.05$.

\section{Discussion}

Moderate leaf curling minimizes shadowing between leaves and improves crop yield by increasing planting density $[45,46]$. It also reduces leaf transpiration under drought stress [47]. Therefore, studies on leaf living states are of significance. In Oryza sativa, over 70 genes/QTLs for the rolled leaf trait have been reported, and more than 17 genes involved in leaf curling have been cloned [46,48]. Moreover, the last three leaves of a super, high-yielding hybrid rice were rolled (V-shaped) [49]. Leaf curling has also been utilized in maize breeding for compact plant types. Six mutants have been characterized in maize with leaf curling traits $[31,50]$. In soybean, mutants with rolled leaves and genes/QTL associated with rolled leaves have been reported [51]. Recent studies identified two loci related to rolled leaves $(B n U C 1, B n U C 2)$ in rapeseed $[2,38]$. The present study identifies a novel leaf up-curling locus (BnUC3), which may help in breeding and genetic research on leaf living state in rapeseed.

In this study, limited plants were initially used for SNP genotyping to map and locate $B n U C 3$. This approach was inexpensive and practical due to the relatively short genomic 
length corresponding to per cM of B. napus [2,49]. The SSR marker scan designed for the mapping interval compensated for the shortfall in SNP marker nonuniformity in the rapeseed genome and helped narrow down the mapping interval [52,53]. However, these markers were not enough for fine mapping due to a lack of polymorphic SSR markers. Therefore, the genomes of multiple rapeseed accessions were aligned that helped find the structural variation (SV). Further, based on the SVs, InDel markers were developed and used to narrow down the mapping interval. This study thus indicates that the jointed multiple modern marker detection approaches may help map the target locus.

Chlorophyll content and photosynthetic efficiency may affect the yield of rapeseed [54]. In this work, the chlorophyll content did not change significantly between up-curling leaves and flat leaves; however, the photosynthetic efficiency of the plants with the up-curling leaves was lower than those with the flat leaves, possibly associated with the alteration in leaf adaxial-abaxial polarity (unpublished). This phenomenon has been observed in many other species with up-curling leaves [29]. However, it does not imply that up-curling leaf trait may not be used in breeding. Utility of up-curling trait plays roles in increase of planting density and in improvement of planting population light acceptation structure and air ventilation among plants, which are useful in elevating overall yield per unit area.

Furthermore, the gene responsible for the up-curling trait showed a mutation in the conserved region of STMP specific to Brassicaceae. This gene had two copies, unlike other genes with at least three copies in the allotetraploid B. napus. Therefore, the dominant gene readily exhibited the mutant phenotype. Although the photosynthetic efficiency was lower in the mutant, the potential gene responsible for the up-curling of leaves was not found to affect photosynthesis. Therefore, studies should further explore the mechanisms underlying the candidate gene.

\section{Materials and Methods}

\subsection{Plant Materials}

The B. napus line NJAU-M1295 with up-curling leaves from the germplasm bank of Nanjing Agricultural University was crossed with Zhongshuang11 (ZS11) with normal, flat leaves, and the $F_{1}$ was selfed and backcrossed with ' $Z S 11$ ' to generate the $F_{2}$ and $\mathrm{BC}_{1}$ populations, respectively. NJAU-CP3756 with normal, flat-leaf phenotype was also used to create the mapping populations.

\subsection{Determination of Chlorophyll Content and Photosynthetic Efficiency}

Chlorophyll (Chl) and carotenoids were extracted from $0.2 \mathrm{~g}$ of fresh leaves with $50 \mathrm{~mL}$ of $80 \%$ acetone, and the concentrations were measured using an Alpha-1500 spectrophotometer (LASPEC, Shanghai, China) [2]. The chlorophyll a (Chl a), chlorophyll b (Chl b), total Chl, and carotenoid concentrations were measured as described previously $[55,56]$. Each experiment had five biological replicates. The mean values of all the traits were compared between the up-curling leaf and the flat leaf plants by Student's $t$-tests.

The photosynthetic parameters of the plants with up-curling leaves and the plants with flat leaves were determined at the rosette stage using Li-Cor 6400 portable photosynthesis system (Li-Cor Inc., Lincoln, NE, USA) as described by Zhang et al. (2010) [57]. Each experiment had four biological replicates. The mean values of all the traits were compared between the up-curling leaf and the flat leaf plants by Student's $t$-tests.

\subsection{Inheritance of the Leaf Curling Trait}

Genetic segregation was investigated using $\mathrm{F}_{2}$ and backcross populations derived from the parent NJAU-M1295 with up-curling leaves and the parents with the flat leaves (ZS11, NJAU-CP3756). The $\chi^{2}$ test assessed the segregation ratios.

\subsection{SNP Genotyping and Locus Mapping}

Total DNA was isolated from the fresh leaves using a modified cetyltrimethylammonium bromide (CTAB) method [58]. The extracted DNA was digested using RNase 
I (Takara, Dalian, China) to remove RNA, and the DNA concentration was adjusted to $200 \mathrm{ng} \mu \mathrm{L}^{-1}$. DNA samples from three plants with flat leaves and 34 plants with up-curling leaves in the BC1 population (NJAU-M1295 $\times$ ZS11) $\times$ ZS11 were used for SNP genotyping, performed as described previously [59]. Association mapping was conducted to map the locus controlling the leaf curling trait using the SNP markers and leaf shape data, and was performed using software TASSEL 5 [39]. In this analysis, the up-curling phenotype was given a value of 1 , and the normal phenotype was given a value of 0 , and marker genotype was causal variable [60]. This approach is in fact a conventional linkage mapping method for a qualitative trait locus. Chi-square test $\left(\chi^{2}\right)$ was conducted to evaluate the association between SNP markers (M49061 and M02825) and leaf up-curling trait.

After the initial mapping of $B n U C 3$ onto the $\mathrm{A} 02$ chromosome, sequence of the mapped interval on the A02 chromosome were downloaded from B. napus pan-genome information resource (BnPIR; http:/ / cbi.hzau.edu.cn/bnapus/, accessed on 25 October 2021), and SSR markers were identified using SSR Hunter 1.3 program [61], and SSR marker primers were designed using Premier 5.0 [62]. The PCR for the SSR markers was performed as previously described [2]. A total of 232 primer pairs (see Table S1) were designed based on the mapping interval genome sequence of ZS11 (http://cbi.hzau.edu.cn/bnapus/, accessed on 25 October 2021). However, no polymorphic SSR markers were found in the preliminary mapping interval generated by the SNP markers. Further, a canola line NJAUCP3756 from our lab germplasm bank replaced ZS11 to generate the mapping population. The polymorphic SSR markers (BnaA02V0056, BnaA02V0099, BnaA02V0333, BnaA02V0573, and BnaA02V0915) were detected in the $\mathrm{F}_{2}$ population derived from up-curling leaf parent NJAU-M1295 and flat-leaf parent NJAU-CP3756. A total of 584 individuals in this $F_{2}$ population were analyzed to generate a linkage map and determine the chromosome bearing the five SSR markers by JoinMap 4.1 software [63].

Further, the genomic sequences within the preliminary mapping interval were downloaded from B. napus Genome Browser (http:/ / www.genoscope.cns.fr/brassicanapus/, accessed on 25 October 2021) and B. napus pan-genome information resource (BnPIR; http://cbi.hzau.edu.cn/bnapus/, accessed on 25 October 2021) for fine mapping the BnUC3 locus. The sequences of the chromosomal segments obtained from the reference genomes were compared to identify the InDels. Based on this, four InDel marker primers (see Table S1) were designed using Premier 5.0 [62], and two InDel markers (BnaA02INDEL1 and BnaA02INDEL2) were identified as polymorphic, which narrowed the mapping interval. PCR of InDel markers was performed in a $20-\mu \mathrm{L}$ reaction volume using $2 \times$ EasyTaq $^{\circledR}$ PCR SuperMix (Transgen, Beijing, China). Standard PCR program was adopted as follows: an initial denaturation of $94{ }^{\circ} \mathrm{C}$ for $5 \mathrm{~min}$, followed by 35 cycles of denaturation at $94{ }^{\circ} \mathrm{C}$ for $45 \mathrm{~s}$, annealing at Tm (specific for each marker) for $45 \mathrm{~s}$, and extension at $72{ }^{\circ} \mathrm{C}$ for $2 \mathrm{~min}$, and a final extension at $72{ }^{\circ} \mathrm{C}$ for $5 \mathrm{~min}$. Then, the polymorphic bands were separated in agarose gel $(1 \%)$.

\subsection{Candidate Gene Analysis}

Homologous sequence and annotation information of the mapped interval on the A02 chromosome were downloaded from B. napus Genome Browser (http:/ / www.genoscope. cns.fr/brassicanapus/, accessed on 25 October 2021) and B. napus pan-genome information resource (BnPIR; http:/ / cbi.hzau.edu.cn/bnapus / , accessed on 25 October 2021) to analyze the candidate gene.

\subsection{Sequence Analysiss}

Genomic regions containing the CDS of the candidate genes were cloned from NJAUM1295 and NJAU-CP3756. The specific primers (see Table S2) were designed using Premier 5.0 [62]. The PCR program was adopted as described previously [64]. The amplified fragment was inserted into the pEASY-Blunt Cloning Kit vector (TransGen, Beijing, China) and sequenced. The resulting sequences were aligned using Clustal X software [65]. 


\subsection{Quantitative RT-PCR Analysis}

Total RNA was isolated from the leaves at the tillering stage using the RNAprep Pure Plant Kit (BioTeke, Beijing, China). The first-strand complementary DNA was synthesized using a reverse transcription kit (Takara, Tokyo, Japan). The specific primers (see Table S3) of candidate genes detected in the mapped interval and reference gene Actin 7 were designed using Premier 5.0 [62]. The qRT-PCR was performed on a CFX96 Touch RealTime PCR Detection System (BIO-RAD, Hercules, CA, USA) with SYBR Green Real-time PCR Master Mix (Toyobo, Tokyo, Japan). Three biological replicates were used. Relative expression levels were calculated using the $2^{-\Delta \Delta C t}$ method [66]. The gene expression comparison between the up-curling leaf and the flat leaf plants was conducted by Student's $t$-tests.

\section{Conclusions}

A new leaf mutant with an up-curling leaf, NJAU-M1295, was discovered from our $B$. napus germplasm. Inheritance studies showed that the up-curling trait was controlled by one dominant locus mapped to an interval of $92.0 \mathrm{~kb}$ on the Brassica A02 chromosome using SNP, SSR, and InDel markers. BnaA02T0157000ZS was identified as the candidate gene based on sequencing and gene expression analyses. Further analysis of individual plants revealed an adverse effect of up-curling leaf on photosynthetic efficiency. To conclude, the study provides a theoretical foundation for elucidating the leaf up-curling mechanism and breeding B. napus.

Supplementary Materials: The following are available online at https:/ / www.mdpi.com/article/ 10.3390/ijms222111693/s1, Table S1: The designed primers of SSR and InDel markers used in this study (.doc), Table S2: The designed primers of comparative sequencing used in this study (.doc), Table S3: The designed primers of quantitative RT-PCR used in this study (.doc).

Author Contributions: R.G. conceived and designed the study. S.W. performed many of the experiments and wrote the manuscript. R.G. advised on the experiments and modified the manuscript. Z.Q., X.J., M.Y., W.C., Y.W., F.N. and Y.G. took part in the DNA extraction, marker experiments, and sequence analysis. All authors have read and agreed to the published version of the manuscript.

Funding: This research was supported financially by the National Natural Science Foundation of China (31771832), the Fundamental Research Funds for the Central Universities (Y0202100126), and the Cyrus Tang Seed Innovation Center, Nanjing Agricultural University. The funders provided the financial support to the research, but had no role in the design of the study, analysis, interpretations of data, or in writing the manuscript.

Institutional Review Board Statement: Not applicable.

Informed Consent Statement: Not applicable.

Conflicts of Interest: The authors declare no conflict of interest.

\section{References}

1. Lang, Y.; Zhang, Z.; Gu, X.; Yang, J.; Qingsen, Z. Physiological and ecological effect of crimpy leaf character in rice (Oryza sativa L.). II. Photosynthetic character; dry mass production and yield forming. Agron. Sin. 2004, 30, 883-887.

2. Yang, M.; Huang, C.; Wang, M.; Fan, H.; Wan, S.; Wang, Y.; He, J.; Guan, R. Fine mapping of an up-curling leaf locus (BnUC1) in Brassica napus. BMC Plant Biol. 2019, 19, 324. [CrossRef]

3. Dong, J.; Huang, H. Auxin polar transport flanking incipient primordium initiates leaf adaxial-abaxial polarity patterning. J. Integr. Plant Biol. 2018, 60, 455-464. [CrossRef]

4. Waites, R.; Hudson, A. phantastica: A gene required for dorsoventrality of leaves in Antirrhinum majus. Development 1995, 121, 2143-2154. [CrossRef]

5. Waites, R.; Selvadurai, H.R.; Oliver, I.R.; Hudson, A. The PHANTASTICA Gene Encodes a MYB Transcription Factor Involved in Growth and Dorsoventrality of Lateral Organs in Antirrhinum. Cell 1998, 93, 779-789. [CrossRef]

6. Iwakawa, H.; Takahashi, H.; Machida, Y.; Machida, C. Roles of ASYMMETRIC LEAVES2 (AS2) and Nucleolar Proteins in the Adaxial-Abaxial Polarity Specification at the Perinucleolar Region in Arabidopsis. Int. J. Mol. Sci. 2020, 21, 7314. [CrossRef] [PubMed]

7. McConnell, J.; Barton, M. Leaf polarity and meristem formation in Arabidopsis. Development 1998, 125, 2935-2942. [CrossRef] 
8. McConnell, J.R.; Emery, J.; Eshed, Y.; Bao, N.; Bowman, J.; Barton, M.K. Role of PHABULOSA and PHAVOLUTA in deter-mining radial patterning in shoots. Nature 2001, 411, 709-713. [CrossRef]

9. Itoh, J.-I.; Hibara, K.-I.; Sato, Y.; Nagato, Y. Developmental Role and Auxin Responsiveness of Class III Homeodomain Leucine Zipper Gene Family Members in Rice. Plant Physiol. 2008, 147, 1960-1975. [CrossRef]

10. Johnston, R.; Candela, H.; Hake, S.; Foster, T. The maize milkweed pod1 mutant reveals a mechanism to modify organ morphology. Genes 2010, 48, 416-423. [CrossRef]

11. Yu, T.; Guan, C.; Wang, J.; Sajjad, M.; Ma, L.; Jiao, Y. Dynamic patterns of gene expression during leaf initiation. J. Genet. Genom. 2017, 44, 599-601. [CrossRef]

12. Rong, F.; Chen, F.; Huang, L.; Zhang, J.; Zhang, C.; Hou, D.; Cheng, Z.; Weng, Y.; Chen, P.; Li, Y. A mutation in class III homeodomain-leucine zipper (HD-ZIP III) transcription factor results in curly leaf (cul) in cucumber (Cucumis sativus L.). Theor. Appl. Genet. 2018, 132, 113-123. [CrossRef]

13. Manuela, D.; Xu, M. Patterning a Leaf by Establishing Polarities. Front. Plant Sci. 2020, 11, 568730. [CrossRef]

14. Candela, H.; Johnston, R.; Gerhold, A.; Foster, T.; Hake, S. The milkweed pod1 gene encodes a KANADI protein that is required for abaxial/adaxial patterning in maize leaves. Plant. Cell. 2008, 20, 2073-2087. [CrossRef]

15. Wu, G.; Lin, W.-C.; Huang, T.; Poethig, R.S.; Springer, P.S.; Kerstetter, R.A. KANADI1 regulates adaxial-abaxial polarity in Arabidopsis by directly repressing the transcription of ASYMMETRIC LEAVES2. Proc. Natl. Acad. Sci. USA 2008, 105, 16392-16397. [CrossRef]

16. Emery, J.F.; Floyd, S.K.; Alvarez, J.; Eshed, Y.; Hawker, N.P.; Izhaki, A.; Baum, S.F.; Bowman, J.L. Radial patterning of Ara-bidopsis shoots by class IIIHD-ZIP and KANADI genes. Current Biol. 2003, 13, 1768-1774. [CrossRef]

17. Romanova, M.; Maksimova, A.; Pawlowski, K.; Voitsekhovskaja, O. YABBY Genes in the Development and Evolution of Land Plants. Int. J. Mol. Sci. 2021, 22, 4139. [CrossRef]

18. Zhang, T.; Li, C.; Li, D.; Liu, Y.; Yang, X. Roles of YABBY transcription factors in the modulation of morphogenesis, development, and phytohormone and stress responses in plants. J. Plant Res. 2020, 133, 751-763. [CrossRef]

19. Sarojam, R.; Sappl, P.G.; Goldshmidt, A.; Efroni, I.; Floyd, S.K.; Eshed, Y.; Bowman, J.L. Differentiating Arabidopsis Shoots from Leaves by Combined YABBY Activities. Plant Cell 2010, 22, 2113-2130. [CrossRef] [PubMed]

20. Pekker, I.; Alvarez, J.P.; Eshed, Y. Auxin Response Factors Mediate Arabidopsis Organ Asymmetry via Modulation of KANADI Activity. Plant Cell 2005, 17, 2899-2910. [CrossRef]

21. Guan, C.; Wu, B.; Yu, T.; Wang, Q.; Krogan, N.T.; Liu, X.; Jiao, Y. Spatial Auxin Signaling Controls Leaf Flattening in Arabidopsis. Curr. Biol. 2017, 27, 2940-2950.e4. [CrossRef]

22. Kelley, D.; Arreola, A.; Gallagher, T.L.; Gasser, C.S. ETTIN (ARF3) physically interacts with KANADI proteins to form a functional complex essential for integument development and polarity determination in Arabidopsis. Development 2012, 139, 1105-1109. [CrossRef]

23. Du, F.; Gong, W.; Boscá, S.; Tucker, M.; Laux, T. Dose-dependent AGO1-mediated inhibition of the miRNA165/166 pathway modulates stem cell maintenance in arabidopsis shoot apical meristem. Plant. Commun. 2019, 1, 100002. [CrossRef]

24. Kirolinko, C.; Hobecker, K.; Wen, J.; Mysore, K.S.; Niebel, A.; Blanco, F.A.; Zanetti, M.E. Auxin Response Factor 2 (ARF2), ARF3, and ARF4 Mediate Both Lateral Root and Nitrogen Fixing Nodule Development in Medicago truncatula. Front. Plant Sci. 2021, 12, 659061. [CrossRef]

25. Yifhar, T.; Pekker, I.; Peled, D.; Friedlander, G.; Pistunov, A.; Sabban, M.; Wachsman, G.; Alvarez, J.P.; Amsellem, Z.; Eshed, Y. Failure of the tomato trans-acting short interfering RNA program to regulate AUXIN RESPONSE FACTOR3 and ARF4 un-derlies the wiry leaf syndrome. Plant. Cell. 2012, 24, 3575-3589. [CrossRef]

26. Nagasaki, H.; Itoh, J.-I.; Hayashi, K.; Hibara, K.-I.; Satoh-Nagasawa, N.; Nosaka, M.; Mukouhata, M.; Ashikari, M.; Kitano, H.; Matsuoka, M.; et al. The small interfering RNA production pathway is required for shoot meristem initiation in rice. Proc. Natl. Acad. Sci. USA 2007, 104, 14867-14871. [CrossRef]

27. Nogueira, F.T.; Madi, S.; Chitwood, D.H.; Juarez, M.T.; Timmermans, M.C. Two small regulatory RNAs establish opposing fates of a developmental axis. Genes Dev. 2007, 21,750-755. [CrossRef]

28. Qi, J.; Wu, B.; Feng, S.; Lü, S.; Guan, C.; Zhang, X.; Qiu, D.; Hu, Y.; Zhou, Y.; Li, C.; et al. Mechanical regulation of organ asymmetry in leaves. Nat. Plants 2017, 3, 724-733. [CrossRef]

29. Fang, L.; Zhao, F.; Cong, Y.; Sang, X.; Du, Q.; Wang, D.; Li, Y.; Ling, Y.; Yang, Z.; He, G. Rolling-leaf14 is a 2 OG-Fe (II) oxygenase family protein that modulates rice leaf rolling by affecting secondary cell wall formation in leaves. Plant Biotechnol. J. 2012, 10, 524-532. [CrossRef]

30. Jenks, M.A.; Rashotte, A.M.; Tuttle, H.A.; Feldmann, K.A. Mutants in Arabidopsis thaliana Altered in Epicuticular Wax and Leaf Morphology. Plant Physiol. 1996, 110, 377-385. [CrossRef]

31. Pan, Z.; Liu, M.; Zhao, H.; Tan, Z.; Liang, K.; Sun, Q.; Gong, D.; He, H.; Zhou, W.; Qiu, F. ZmSRL5 is involved in drought tolerance by maintaining cuticular wax structure in maize. J. Integr. Plant Biol. 2020, 62, 1895-1909. [CrossRef] [PubMed]

32. Aharoni, A.; Dixit, S.; Jetter, R.; Thoenes, E.; van Arkel, G.; Pereira, A. The SHINE Clade of AP2 Domain Transcription Factors Activates Wax Biosynthesis, Alters Cuticle Properties, and Confers Drought Tolerance when Overexpressed in Arabidopsis. Plant Cell 2004, 16, 2463-2480. [CrossRef] [PubMed]

33. Chen, W.; Wan, S.; Shen, L.; Zhou, Y.; Huang, C.; Chu, P.; Guan, R. Histological, Physiological, and Comparative Proteomic Analyses Provide Insights into Leaf Rolling in Brassica napus. J. Proteome Res. 2018, 17, 1761-1772. [CrossRef] 
34. Esteve-Bruna, D.; Pérez-Pérez, J.M.; Ponce, M.R.; Micol, J.L. incurvata13, a Novel Allele of AUXIN RESISTANT6, Reveals a Specific Role for Auxin and the SCF Complex in Arabidopsis Embryogenesis, Vascular Specification, and Leaf Flatness. Plant Physiol. 2013, 161, 1303-1320. [CrossRef]

35. Pérez-Pérez, J.M.; Ponce, M.R.; Micol, J.L. The UCU1 Arabidopsis Gene Encodes a SHAGGY/GSK3-like Kinase Required for Cell Expansion along the Proximodistal Axis. Dev. Biol. 2002, 242, 161-173. [CrossRef] [PubMed]

36. Nam, K.H.; Li, J. BRI1/BAK1, a Receptor Kinase Pair Mediating Brassinosteroid Signaling. Cell 2002, 110, 203-212. [CrossRef]

37. Shang, Y.; Lee, M.M.; Li, J.; Nam, K.H. Characterization of cp3 reveals a new bri1 allele, bri1-120, and the importance of the LRR domain of BRI1 mediating BR signaling. BMC Plant Biol. 2011, 11, 8. [CrossRef] [PubMed]

38. Huang, C.; Yang, M.; Shao, D.; Wang, Y.; Wan, S.; He, J.; Meng, Z.; Guan, R. Fine mapping of the BnUC2 locus related to leaf up-curling and plant semi-dwarfing in Brassica napus. BMC Genom. 2020, 21, 530. [CrossRef]

39. Bradbury, P.J.; Zhang, Z.; Kroon, D.E.; Casstevens, T.M.; Ramdoss, Y.; Buckler, E.S. TASSEL: Software for association mapping of complex traits in diverse samples. Bioinformatics 2007, 23, 2633-2635. [CrossRef]

40. Gu, X.-L.; Wang, H.; Huang, H.; Cui, X.-F. SPT6L Encoding a Putative WG/GW-Repeat Protein Regulates Apical-Basal Polarity of Embryo in Arabidopsis. Mol. Plant 2012, 5, 249-259. [CrossRef]

41. Chen, C.; Shu, J.; Li, C.; Thapa, R.K.; Nguyen, V.; Yu, K.; Yuan, Z.-C.; Kohalmi, S.E.; Liu, J.; Marsolais, F.; et al. RNA polymerase II-independent recruitment of SPT6L at transcription start sites in Arabidopsis. Nucleic Acids Res. 2019, 47, 6714-6725. [CrossRef]

42. Yu, Z.; Xu, Y.; Zhu, L.; Zhang, L.; Liu, L.; Zhang, D.; Li, D.; Wu, C.; Huang, J.; Yang, G.; et al. The Brassicaceae-specific secreted peptides, STMPs, function in plant growth and pathogen defense. J. Integr. Plant Biol. 2020, 62, 403-420. [CrossRef]

43. Zolman, B.K.; Martinez, N.; Millius, A.; Adham, A.R.; Bartel, B. Identification and characterization of Arabidopsis in-dole-3butyric acid response mutants defective in novel peroxisomal enzymes. Genetics 2008, 180, 237-251. [CrossRef] [PubMed]

44. Wiszniewski, A.A.; Zhou, W.; Smith, S.M.; Bussell, J.D. Identification of two Arabidopsis genes encoding a peroxisomal oxidoreductase-like protein and an acyl-CoA synthetase-like protein that are required for responses to pro-auxins. Plant. Mol. Biol. 2009, 69, 503-515. [CrossRef]

45. Duncan, W.G. Leaf Angles, Leaf Area, and Canopy Photosynthesis 1. Crop. Sci. 1971, 11, 482-485. [CrossRef]

46. Liu, X.; Li, M.; Liu, K.; Tang, D.; Sun, M.; Li, Y.; Shen, Y.; Du, G.; Cheng, Z. Semi-Rolled Leaf2modulates rice leaf rolling by regulating abaxial side cell differentiation. J. Exp. Bot. 2016, 67, 2139-2150. [CrossRef]

47. Verma, A.; Niranjana, M.; Jha, S.K.; Mallick, N.; Agarwal, P. Vinod QTL detection and putative candidate gene prediction for leaf rolling under moisture stress condition in wheat. Sci. Rep. 2020, 10, 18696. [CrossRef]

48. Qiang, Z.; Zheng, T.; Long, H.; Wang, C.; Nafisah; Charles, J.; Zhang, W.; Xu, J.; Li, Z.; Istvan, R. Joint Mapping and Allele Mining of the Rolled Leaf Trait in Rice (Oryza sativa L.). PLoS ONE 2016, 11, e0158246.

49. Yuan, L.P. Super-high yield hybrid rice breeding. Hybrid Rice 1997, 12, 1-6.

50. Gao, L.; Yang, G.; Li, Y.; Fan, N.; Li, H.; Zhang, M.; Xu, R.; Zhao, A.; Ni, Z.; Zhang, Y. Fine mapping and candidate gene analysis of a QTL associated with leaf rolling index on chromosome 4 of maize (Zea mays L.). Theor. Appl. Genet. 2019, 132, 3047-3062. [CrossRef]

51. Wang, X.; Liu, C.; Tu, B.; Li, Y.; Chen, H.; Zhang, Q.; Liu, X. Characterization on a Novel Rolled Leaves and Short Petioles Soybean Mutant Based on Seq-BSA and RNA-seq Analysis. J. Plant Biol. 2021, 1-17. [CrossRef]

52. Wang, Y.; He, Y.; Yang, M.; He, J.; Xu, P.; Shao, M.; Chu, P.; Guan, R. Fine mapping of a dominant gene conferring chloro-phylldeficiency in Brassica napus. Sci. Rep. 2016, 6, 31419. [CrossRef] [PubMed]

53. Liu, Y.; Zhou, X.; Yan, M.; Wang, P.; Wang, H.; Xin, Q.; Yang, L.; Hong, D.; Yang, G. Fine mapping and candidate gene analysis of a seed glucosinolate content QTL; qGSL-C2; in rapeseed (Brassica napus L.). Theor. Appl. Genet. 2020, 133, 479-490. [CrossRef] [PubMed]

54. Zangani, E.; Afsahi, K.; Shekari, F.; Mac Sweeney, E.; Mastinu, A. Nitrogen and Phosphorus Addition to Soil Improves Seed Yield, Foliar Stomatal Conductance, and the Photosynthetic Response of Rapeseed (Brassica napus L.). Agriculture 2021, 11, 483. [CrossRef]

55. Arnon, D.I. Copper enzymes in isolated chloroplasts. Polyphenoloxidase in Beta vulgaris. Plant Physiol. 1949, 24, 1-15. [CrossRef] [PubMed]

56. Chu, P.; Yan, G.; Yang, Q.; Zhai, L.; Zhang, C.; Zhang, F.; Guan, R. iTRAQ-based quantitative proteomics analysis of Brassica napus leaves reveals pathways associated with chlorophyll deficiency. J. Proteomics. 2015, 113, 244-259. [CrossRef]

57. Zhang, R.; Liu, H.; Zhao, H.; Hu, S. Comparison of two protein extraction methods for proteomic analysis of chloro-phyll-deficient mutants in Brassica juncea L. Prog. Biochem. Biophys. 2010, 37, 1025-1032. [CrossRef]

58. Porebski, S.; Bailey, L.G.; Baum, B.R. Modification of a CTAB DNA extraction protocol for plants containing high polysaccha-ride and polyphenol components. Plant. Mol. Biol. Rep. 1997, 15, 8-15. [CrossRef]

59. Wang, Y.; He, J.; Yang, L.; Wang, Y.; Chen, W.; Wan, S.; Chu, P.; Guan, R. Fine mapping of a major locus controlling plant height using a high-density single-nucleotide polymorphism map in Brassica napus. Theor. Appl. Genet. 2016, 129, 1479-1491. [CrossRef]

60. Weir, B.S. Genetic Data Analysis II; Sinauer Associates Inc.: Sunderland, MA, USA, 1997. [CrossRef]

61. Li, Q.; Wan, J.-M. SSRHunter: Development of a local searching software for SSR sites. Hereditas 2005, 27, 808-810.

62. Singh, V.K.; Mangalam, A.; Dwivedi, S.; Naik, S. Primer Premier: Program for Design of Degenerate Primers from a Protein Sequence. Biotechniques 1998, 24, 318-319. [CrossRef] 
63. Ooijen, J.W.V. JoinMap 4, Software for the Calculation of Genetic Linkage Maps in Experimental Populations; Kyazma BV: Wageningen, The Netherlands, 2006.

64. Wang, Y.; Wan, S.; Fan, H.; Yang, M.; Li, W.; Guan, R. A sulfotransferase gene BnSOT-like1 has a minor genetic effect on seed glucosinolate content in Brassica napus. Crop. J. 2020, 8, 855-865. [CrossRef]

65. Thompson, J.D.; Gibson, T.J.; Frédéric, P.; Franois, J.; Higgins, D.G. The CLUSTAL_X Windows Interface. Flexible Strategies for Multiple Sequence Alignment Aided by Quality Analysis Tools. Nucleic Acids Res. 1997, 24, 4876-4882. [CrossRef]

66. Livak, K.J.; Schmittgen, T.D. Analysis of relative gene expression data using real-time quantitative PCR and the 2(T)(-Delta Delta C) method. Methods 2001, 25, 402-408. [CrossRef] 